\title{
Small Core Flood Experiments for Foam EOR - Screening Surfactant Applications
}

\author{
S.A. Jones ${ }^{1}$, V. van der Bent ${ }^{1}$, R. Farajzadeh ${ }^{1,2}$, W. R. Rossen ${ }^{1}$ and S. Vincent-Bonnieu ${ }^{2}$ \\ 1 TU Delft \\ 2 Shell Global Solution International
}

Aqueous foams are a means of increasing the sweep efficiency of enhanced oil recovery processes. An understanding of how a foam behaves in the presence of oil is therefore of great importance when selecting suitable surfactants for EOR processes. The consensus is currently that the most reliable method for determining the foam behavior in the presence of oil is to inject foam through a rock core. Coreflood tests, however, are typically carried out using large rock cores (e.g. diameter $=4 \mathrm{~cm}$, length $=40 \mathrm{~cm}$ or longer), and hence foam flow tests can take days or weeks to achieve steady-state flow.

In this study, we present the preliminary results for a core-flood system where the rock core is pen-sized $($ diameter $=1 \mathrm{~cm}$, length $=17 \mathrm{~cm}$ ). These small cores allow for short-duration foam flow tests, where steady-state flow is achieved in a few hours. Using this system, the foam quality/effective viscosity response curves can be plotted, both with and without oil in the system. These small size cores then enable rapid screening of surfactants and foam properties in different rocks and with different oils. Benefits and limitations of these small coreflood experiments are discussed. 


\section{Introduction}

Aqueous foams play an important role in many industrial processes, from ore separation by froth flotation to enhanced oil recovery (EOR). In the latter case, the foam is used as a means of increasing the sweep efficiency through the oil bearing rock. When gas is used as a means of enhancing oil recovery the gas tends to rise to the top of the reservoir, or finger through the oil, because of its lower density and viscosity, and to prematurely reach the producers through high-permeability channels. This results in inefficient and costly utilization of the gas. Injection of gas in the form of "foam" can potentially solve the above-mentioned problems. It is therefore of great importance to have a good understanding of foam flow behavior in complex porous media such as rock.

A range of tests, such as bulk foam or micromodel tests, can be carried out to study foam stability, especially in the presence of oil. However, it is has been suggested that there is no reliable correlation between the bulk foam or micromodel behavior and the foam behavior in a rock (Mannhardt et al. 2000; Vikingstad and Aarra, 2009; Farajzadeh et al., 2012; Andrianov et al., 2012; Simjoo et al., 2013). The general consensus is that to be able to obtain detailed information on the foam behavior, especially in the presence of oil, core flood studies must be carried out under representative conditions in representative porous media.

Core flood studies have been carried out using many different types of cores (Kristiansen and Holt, 1992; Mannhardt et al. 2000; Kovscek and Bertin, 2003; Zitha et al. 2006; Nguyen et al., 2009; Farajzadeh et al., 2009, 2010), sand packs (Khatib et al. 1988; Osterloh and Jante, 1992; Apaydin and Kovscek, 2001; Ma et al. 2013) and bead packs (Khatib et al. 1988; Falls et al. 1989; Aronson et al. 1994). These tests have been very useful in providing information on a wide range of aspects of foam behavior, from the effect of surfactant type and concentration, to the interaction of the foam with oil, to foam flow properties such as apparent viscosity and mobility control. The information from these core flood tests can also be fed back into the foam models (Ma et al., 2013; Boeije and Rossen, 2013; Ma et al. 2014). The cores used in these tests typically, but not always (Moradi-Araghi et al, 1997; Nguyen et al., 2009; Farajzadeh et al., 2009), have diameters of at least $3.5 \mathrm{~cm}$, with lengths of $30 \mathrm{~cm}$ and above, and these larger pore volume systems have the advantage that any small heterogeneities in the rock have no significant effect on the foam behavior.

However, larger-scale cores can sometimes take days to achieve steady state flow (Persoff et al., 1991; Simjoo et al., 2013). If we wish to screen a large number of surfactants, to test which is the optimal for a specific reservoir rock or for a particular oil composition, then we would like to work with a system that reaches steady state rapidly.

In the current series of tests, foam flood experiments were performed using a small core-flood system (SCFS), where the rock core is pen-sized, with a diameter of $1 \mathrm{~cm}$ and length of $17 \mathrm{~cm}$. This small core allows for short-duration foam flow tests, as compared to longer-core experiments, with a steady state typically being achieved in two to three hours. The small pore volume of the core also means that the volume of surfactant required to do a full foam quality scan is small. The SCFS therefore has the advantage of being economical in both time and resources, making it an ideal tool for the rapid screening of surfactants in porous media for specific applications.

\section{Experimental Method}

The cores used for these tests were $1 \mathrm{~cm}$ in diameter, $17 \mathrm{~cm}$ long samples of Bentheimer sandstone (permeability, $\mathrm{k},=0.989 \mathrm{D}$; porosity, $\phi,=0.23$ ). The core holder was an aluminum tube with internal diameter, ID, $=1.1 \mathrm{~cm}$ and wall thickness of $0.95 \mathrm{~cm}$. The rock sample was coated in a thin layer of epoxy resin (effective core diameter after coating $=0.94 \mathrm{~cm}$ ) before being placed in the core holder. Instead of applying a confining pressure to the core, epoxy resin was then injected through a side entrance point to seal the core in position and to prevent any of the test fluids from bypassing along 
the side of the core. Multiple cores were available for these tests, meaning that new cores could be used for each surfactant mixture and especially for tests where oil was introduced to the core.

Because of the very small pore volume of the core $\left(2.71 \mathrm{~cm}^{3}\right)$ the volume of the experimental set-up (pipes, connectors etc) was kept as small as possible, in order to keep system errors to a minimum,. The full experimental set-up is shown in Figure 1. The system was connected together using $0.08 \mathrm{~mm}$ ID PTFE or PEEK tubing, with $3.2 \mathrm{~mm}$ junctions and valves.

The surfactant solution and nitrogen were co-injected from the bottom of the core at a constant total flow rate of $0.1 \mathrm{ml} / \mathrm{min}$ (equivalent to a superficial velocity of $2.4 \times 10^{-5} \mathrm{~m} / \mathrm{s}$ or $6.75 \mathrm{ft} / \mathrm{day}$ ) to generate the foam. The surfactant solution was injected using a double-piston displacement pump. The nitrogen gas was supplied from a cylinder, at a pressure of 60 bar, to the mass flow controller.

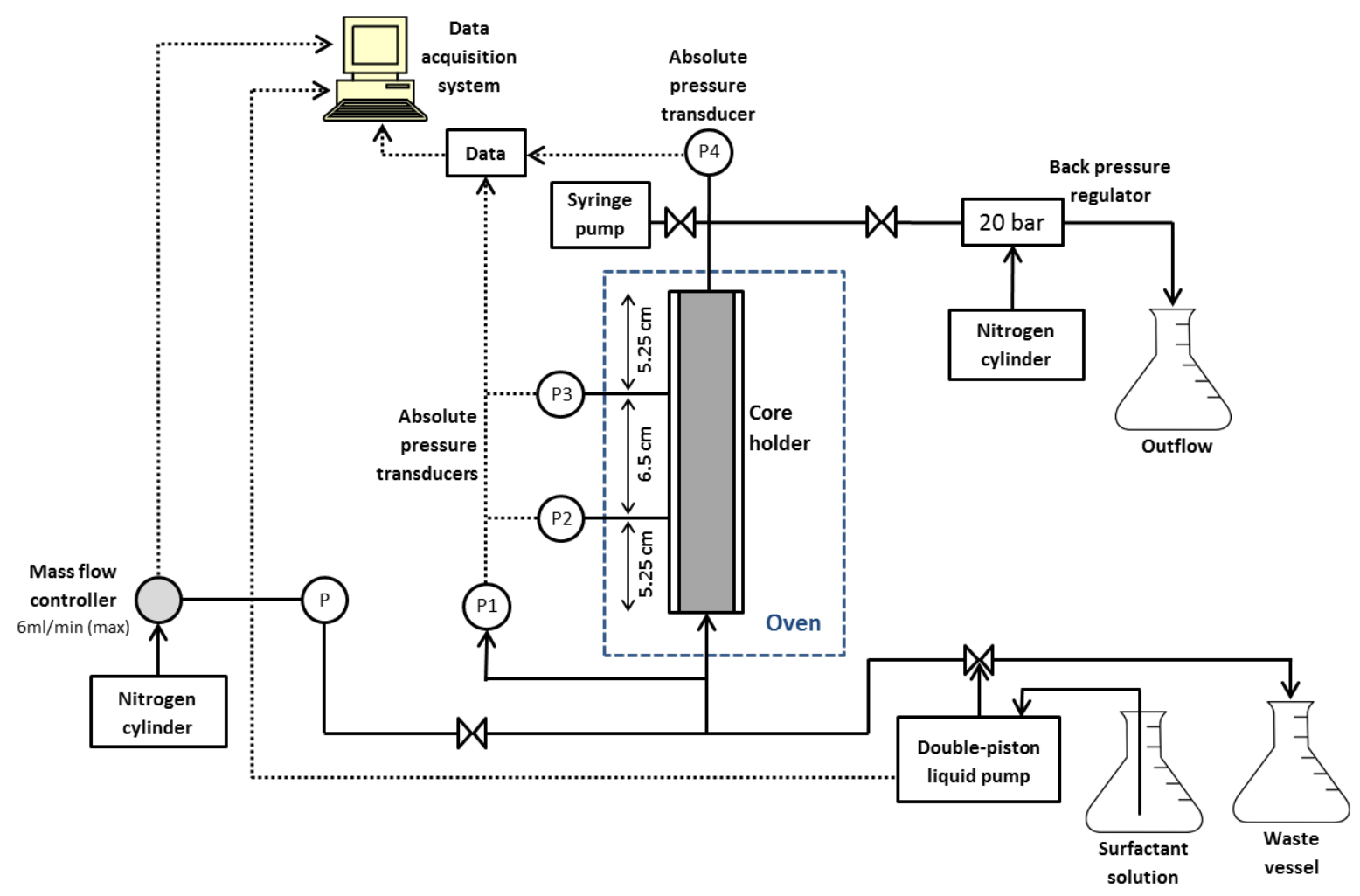

Figure 1 Schematic diagram of the experimental set-up.

Pressure measurements were made using four absolute pressure transducers $-P 1$ was tapped into the input line at the bottom of the core, $P 2$ and $P 3$ were connected to two taps in the core (Figure1), and $P 4$ was located at the outlet of the core, before the back pressure regulator. During each core flood test the injected foam quality, $f_{g}$, was varied and the resultant pressure drop over the core, either the total pressure drop $(P 1-P 4)$ or the drop over the central section of the core $(P 2-P 3)$, was measured. All the experiments were carried out with a back-pressure of 20 bar. The back-pressure regulator used was a locally modified dome-loaded back pressure regulator with a dead volume of approximately $1 \mathrm{ml}$.

A test screening of four commercially available surfactants (Table 1) was made, in an oil-free core, at $55^{\circ} \mathrm{C}$. Five different solutions (detailed in Table 2) were made with the four surfactants. Three solutions contained a single surfactant and two solutions contained a mix of two different surfactants. 


\section{Results and Discussion - Test Screening in Oil-Free Core}

Considering the steady-state pressure drop across the core for each foam quality the apparent viscosity, $\mu_{a p p}$, of the foam can be calculated using :

$$
\mu_{\text {app }}=\frac{k \nabla P}{\left(u_{l}+u_{g}\right)}
$$

where $k$ is the permeability, $u_{l}$ and $u_{g}$ are the liquid and gas superficial velocities respectively, and, in this case, $\nabla P$ is the pressure gradient across the whole core (calculated from $P 4$ and $P 1$, see Figure 1). We acknowledge that using the pressure drop over the whole core ignores the issues of both the entrance effect (Ettinger and Radke, 1992) and the capillary end effect (Apaydin and Kovscek, 2001). The entrance effect especially, that describes the behavior near the inlet of the core where the injected surfactant solution and gas form a steady-state foam (Ettinger and Radke, 1992), can potentially extend a significant distance along the core, and its length could also change with injected foam quality. If this occurs it could significantly affect the inferred foam mobility and the effect of quality on foam mobility. However, as we are comparing like with like at each foam quality, and because the SCFS is intended as a surfactant screening tool for identifying the most promising surfactants prior to larger scale testing, any errors introduced were considered within acceptable limits.

Plotting $\mu_{a p p}$ as a function of the foam quality, curves were obtained for the five surfactant mixtures tested (Figure 2). The largest apparent viscosity for each surfactant solution occurs at a critical foam quality, $f_{g}{ }^{*}$, for that solution (Alvarez et al. 2001; Boeije and Rossen, 2013; Ma et al. 2014). The curve to the left of $f_{g} *$ describes the low foam quality regime where the flow is influenced by bubble trapping and release, and the apparent viscosity is mainly dependent on the gas flow rate (with shear thinning behavior expected). At foam qualities higher than $f_{g}{ }^{*}$ we observe the high-quality regime, where the foam behavior is dominated by coalescence, and the apparent viscosity is mainly dependent on the liquid superficial velocity, usually dropping sharply as foam quality increases (Osterloh and Jante, 1992; Alvarez et al. 2001).

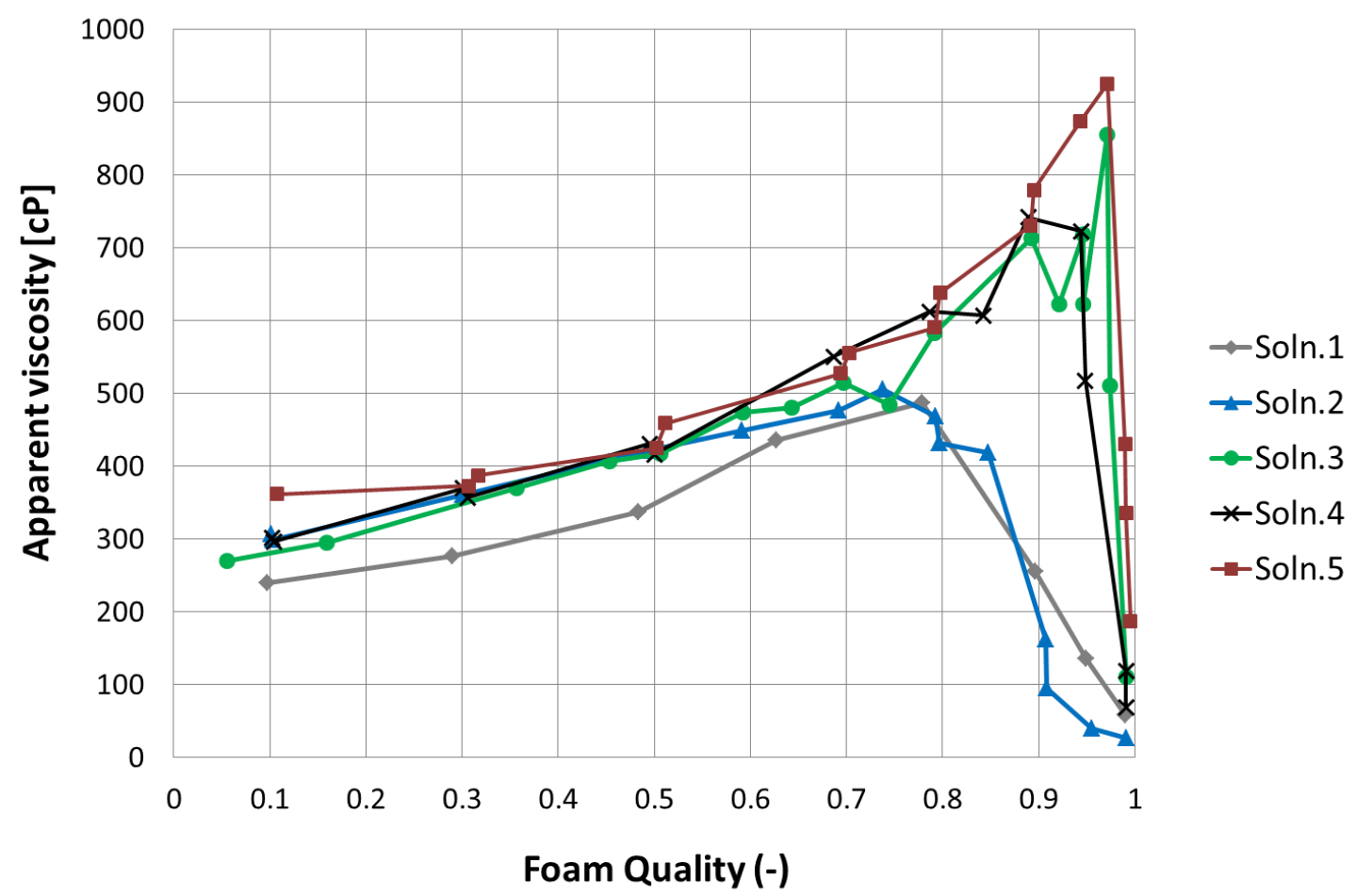

Figure 2: Foam-quality scans for the five surfactant solutions in the oil-free core. The temperature was $55^{\circ} \mathrm{C}$ and the superficial velocity was $2.4 \times 10^{-5} \mathrm{~m} / \mathrm{s}$ for all the tests. The lines joining the points are simply connecting lines to aid the eye in distinguishing between the different data sets. 
For each surfactant, the values of $f_{g}{ }^{*}$, maximum apparent viscosity and the associated maximum pressure gradient $\left(\nabla P_{\max }\right)$ can then be determined from the curves. These measured values are given in Table 3. These quantities are important descriptors of foam stability and can also be used to determine some of the foam parameters for the foam models (Boeije and Rossen, 2013; Ma et al. 2014).

In the low quality regime there is no significant difference in apparent viscosity between the surfactant solutions, up to a foam quality of 0.74 , which is the value of $f_{g} *$ for Solution 2. This observation is in agreement with the description of the low-quality regime as being predominantly defined by bubble trapping and release (Alvarez et al. 2001). It would be expected that the surface tension of each solution also has an effect, through the capillary resistance to flow of gas in the core, but in this case the variation in the surface tensions for the five solutions tested is minimal (Table 2).

At the higher foam qualities the curves begin to diverge. Once a solution reaches its $f_{g} *$ it enters into the high-foam quality regime where the apparent viscosity starts falling. In this regime, as the foam becomes drier, the behavior is determined by foam stability and the capillary pressure. Both foam stability and capillary pressure, and hence the values of $f_{g}{ }^{*}$ and maximum $\mu_{a p p}$ (Table 3 ), are strongly dependent on the surfactant solution being used. The foams with the highest values of $f_{g} *$ have the highest values of maximum $\mu_{a p p}$.

Table 3: Maximum apparent viscosity, with associated maximum pressure gradient and critical foam quality, for each of the surfactant solutions used.

\begin{tabular}{|c|c|c|c|}
\hline Solution No. & $f_{g}{ }^{*}[-]$ & Max $\mu_{\text {app }}[\mathbf{c P}]$ & $\boldsymbol{\nabla P}_{\boldsymbol{m a x}}[\mathbf{P a} / \mathbf{m}]$ \\
\hline $\mathbf{1}$ & 0.78 & 487 & $52.4 \times 10^{5}$ \\
\hline $\mathbf{2}$ & 0.74 & 504 & $57.4 \times 10^{5}$ \\
\hline $\mathbf{3}$ & 0.97 & 855 & $89.7 \times 10^{5}$ \\
\hline $\mathbf{4}$ & 0.91 & 741 & $79.8 \times 10^{5}$ \\
\hline $\mathbf{5}$ & 0.97 & 925 & $96.5 \times 10^{5}$ \\
\hline
\end{tabular}

\section{Results and Discussion - Test Screening in Core Containing Residual Oil}

There is no exact information on the residual oil saturation present in the cores during these tests, unfortunately, or whether the oil saturation changed during the course of the test. One of the drawbacks of the SCFS core is that, because of the very small pore volume $\left(2.71 \mathrm{~cm}^{3}\right)$, it is very difficult to determine the exact quantity of oil in the core. In the current experiments the high apparent viscosities (Figure 4) combine with low interfacial tensions (IOS/IsoparH, $0.31 \mathrm{mN} / \mathrm{m}$ and AOS+Betaine/IsoparH, $1.27 \mathrm{mN} / \mathrm{m}$ at $55^{\circ} \mathrm{C}$ (van der Bent, 2014)) to give capillary numbers $\left(\mathrm{N}_{\mathrm{Ca}}\right)$ in the range $0.02-0.18$. These capillary numbers are very high compared to those obtained during a typical water or surfactant flood. It is therefore highly likely that any residual oil saturation in the core was very low (Lake, 1989), as most of the oil would have been displaced during the foam flood.

This is backed up by the pressure traces obtained during the first foam flood tests with an initial residual oil saturation, when water-flood residual oil was initially present in the core (Figure 3). There is clearly a displacement of a fraction of the oil before we obtain the fullest strength foam, and we require an injection of over $40 \mathrm{PV}$ of foam to reach steady state flow. These tests indicate that the initial water-flood residual oil saturation was not fatal to foam; otherwise the foam could not have built the pressure gradient and the values of capillary number that would mobilize the residual oil with 
this immiscible gas (Simjoo and Zitha, 2013). Following these initial tests, where oil was produced from the core, any further foam flood tests reached steady state rapidly, indicating that no further (significant) oil displacement was necessary to reach steady-state flow behavior. These ongoing tests could therefore be considered as taking place at foam residual oil saturation, which is much lower than water-flood residual oil saturation.

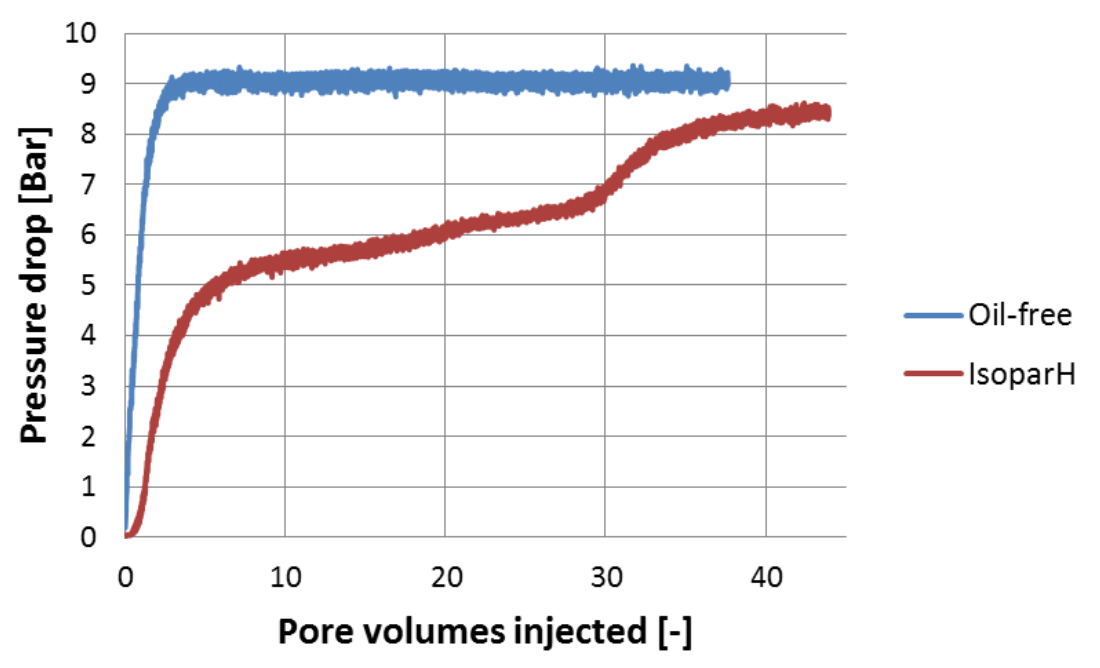

Figure 3: Pressure traces for two foam floods at a foam quality of 0.5 , in both an oil-free core and in a core initially contaminated with Isopar $H$ at water-flood residual saturation.

The foam-quality scan curves, obtained for the two surfactants tested at foam residual oil saturation, are presented in Figure 4 with the oil-free data included for comparison. For Solution 1, the foam residual oil saturation appears to have little or no effect on the steady-state foam behaviour, with no significant change observed in the values of $f_{g} *$ or maximum $\mu_{a p p}$. This either indicates a surfactant with resilient foam behavior in the presence of oil, or that the foam residual oil concentration in this case is extremely low. For solution 5, the foam residual oil has no effect in the low-quality regime, only influencing the behavior in the high-quality regime and causing a reduction in $f_{g} *$ and maximum $\mu_{a p p}$ achieved. In this regime the foam is much drier and therefore much more susceptible to any destabilizing effect of the oil. The coalescence normally observed in the high-quality regime is therefore triggered at lower foam qualities.
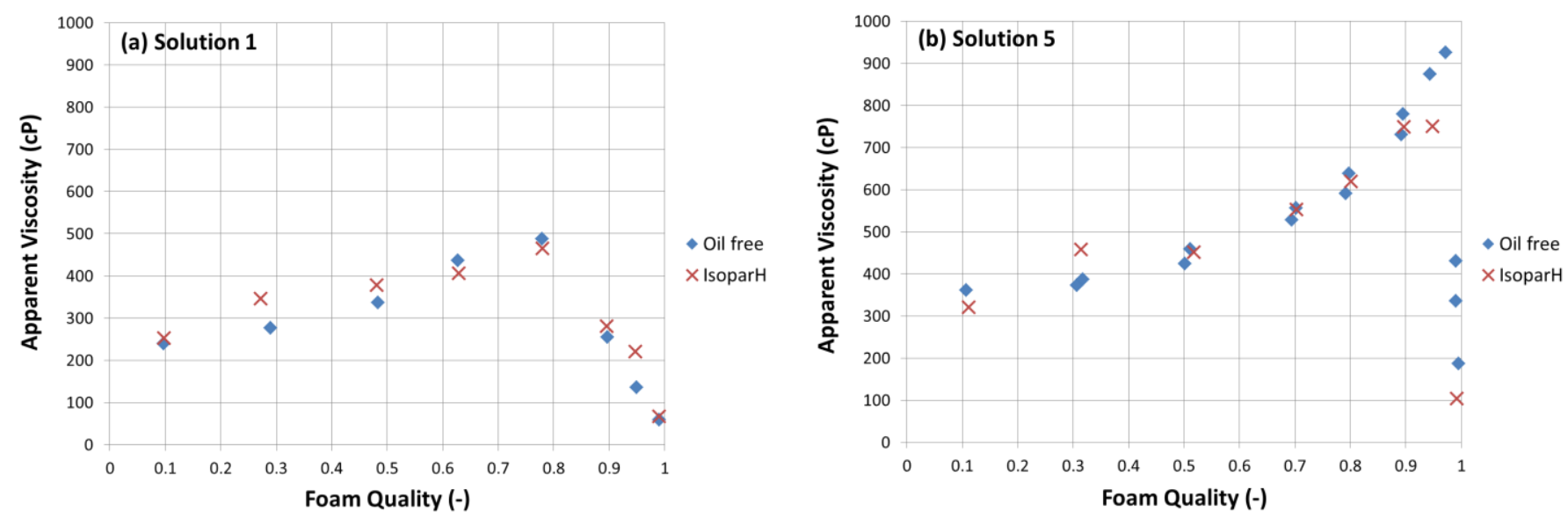

Figure 4: Foam quality scans for (a) Solution 1 and (b) Solution 5, showing the behavior both in the oil-free cores and in the cores contaminated with IsoparH at residual oil saturation. The temperature was $55^{\circ} \mathrm{C}$ and the superficial velocity was $2.4 \times 10^{-5} \mathrm{~m} / \mathrm{s}$ for all the tests. 


\section{Results and Discussion - Comparison with Wider-Diameter Core}

Comparing the previously obtained results of the wider-diameter core (Kapetas et al. 2014), with the data obtained under similar conditions in the SCFS, we obtain the curves shown in Figure 5. In both these experiments, the pressure gradient was calculated from the two pressure taps within the core $(P 2$ and $P 3$ ), and the superficial velocity and temperature were equal in both cases.

Considering the curves, good agreement between the two sets of results is observed in the highquality foam regime. There is also very good agreement in the value of $f_{g}{ }^{*}$, which is approximately equal to $0.91 \pm 0.02$ in both cases. However, there is some discrepancy between the values of maximum apparent viscosity obtained, with values of $1120 \mathrm{cP}$ and $1226 \mathrm{cP}$ being obtained for the SCFS and wider-diameter core respectively.

Most significant however is the deviation between the results in the low-quality regime, with the larger core showing consistently higher apparent viscosities. There is currently no definitive explanation as to why this should occur, but it may have something to do with the fact that the very narrow SCFS core confines the foam flow in some way that alters it, with a possible associated change in bubble trapping and release.

These results would seem to imply that, although the SCFS can be used to provide a quick, economical comparison between different surfactants, the differences in the curve shapes in the low foam-quality regime are large enough that we would not, at this point in time, recommend using this type of system to generate information for a foam model, such as that in STARS (Ma et al. 2014), where the fit of the full curve is important to generate accurate foam parameters.

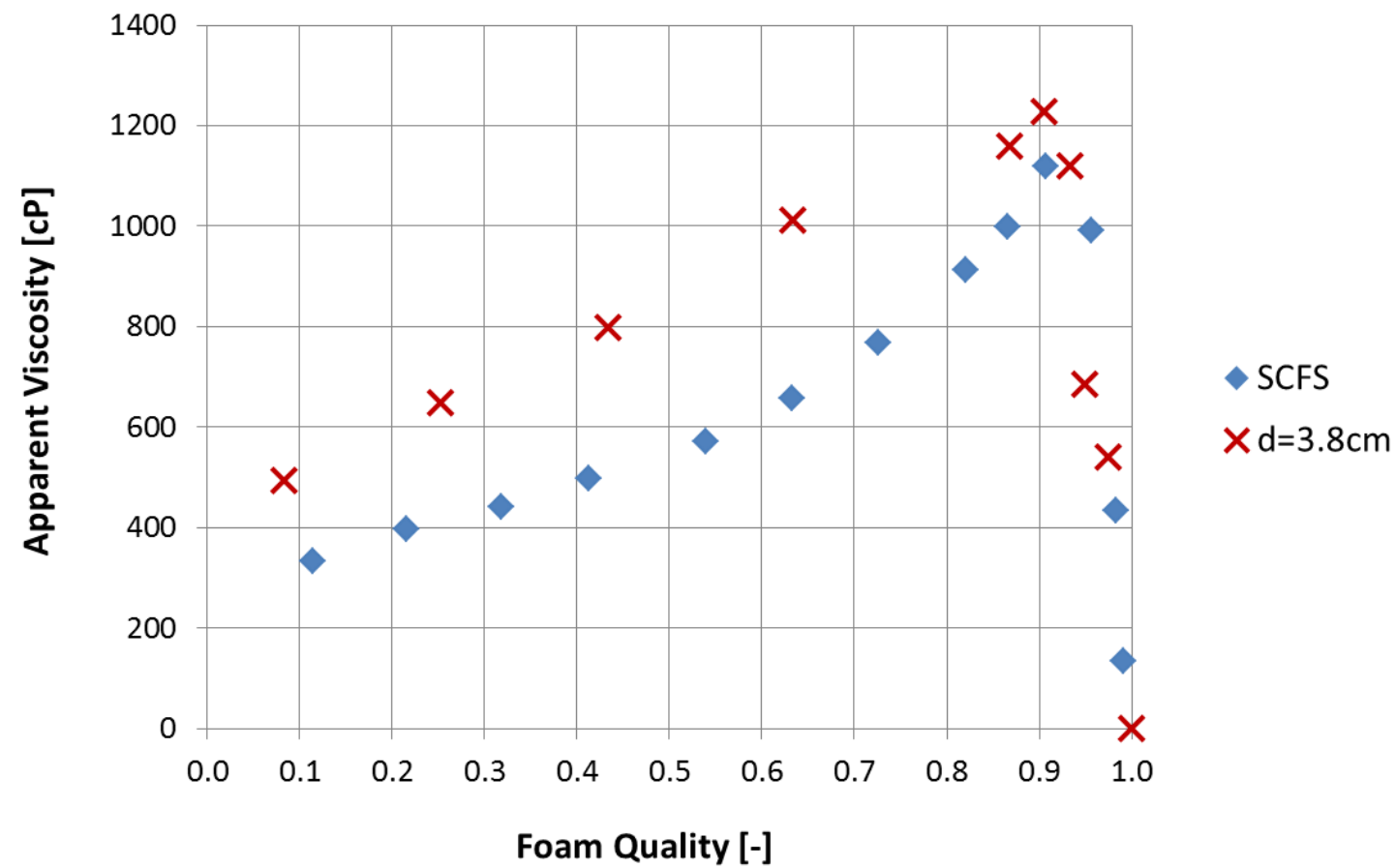

Figure 5: Foam quality scans for $1 \%$ AOS / $1 \%$ brine in the SCFS $(d=1 \mathrm{~cm})$ and wider diameter $(d=3.8 \mathrm{~cm})$ cores. The temperature was $20^{\circ} \mathrm{C}$ and the superficial velocity was $1.58 \times 10^{-5} \mathrm{~m} / \mathrm{s}$ for both tests. 


\section{Conclusions}

The small core-flood set-up (SCFS) has been used to carry out a test screening of five different surfactant solutions, and could be used to rapidly characterize a series of surfactants for their foam strength, resistance to oil, and behaviour as a function of foam quality. It therefore has the potential to be a powerful surfactant screening tool, with the advantage over a large-sized core that less time and material is required for each core flood experiment. The core is also easy to handle and adapt, making it a very flexible tool for foam testing.

In the core-flood tests in the presence of oil, it was found that the initial water-flood residual oil saturation affected the foam, but did not kill it completely, with high enough values of capillary number being generated to mobilize a large fraction of the residual oil. The resultant foam residual oil saturation had very little effect on further foam tests, and did not prevent the creation of strong foam. Late in the experiment this reflects the very low oil saturations in the core resulting from the high values of capillary number. For the two surfactants tested, the foam-residual oil saturation, obtained during the first foam flood, had no effect in the low-foam quality regime, and only showed a destabilizing effect in the high quality regime of Solution 5, reducing $f_{g} *$ and the maximum value of $\mu_{\text {app }}$.

Comparing the foam flow behavior in the SCFS core with that in a larger-diameter core of the same length, we found good agreement in the curves in the high-quality regime. The values of $f_{g}^{*}$ also showed good agreement between the two geometries. However, there was a significant discrepancy in the apparent viscosities measured in the low-quality regime. It is therefore suggested that the SCFS core set-up might not be suitable for determining foam parameters for modelling purposes.

\section{Future Perspectives}

- Further comparison tests with larger-diameter, and longer, cores are required to fully determine the nature, and causes, of the discrepancy in the foam quality scans in the low quality foam regime.

- A selection of different rock cores, with a range of permeabilities, will be tested in order to determine the applicability of the SCFS as a generalised surfactant screening test apparatus.

- CT scans of the SCFS will be used to determine the exact extent of the entrance and end effects.

- Further work is required to accurately determine the residual oil saturation in the SCFS.

- An ongoing technical challenges when working with the SCFS is in the creation of the central pressure taps. Because of the very small core radius, the pressure taps should not extend very far into the core, but they should also not be too shallow, in order to obtain accurate pressure readings.

\section{Acknowledgements}

We acknowledge financial support from Shell Global Solution International and technical support from Michiel Slob. We thank Dr. Koenraad Elewaut and Dr. Ramez Nasralla for their careful review of the manuscript.

\section{References}

Alvarez, J. M., Rivas, H. J. and Rossen, W. R. [2001] Unified model for steady-state foam behavior at high and low foam qualities. SPE Journal, 6 (3), 325-333 
Andrianov, A., Farajzadeh, R., Mahamoodi Nick, M., Talanana, M. and Zitha, P.L.J. [2012] Immiscible foam for enhancing oil recovery: Bulk and porous media experiments. Ind. Eng. Chem. Res. 51 (5), 2214-2226

Apaydin, O. G. and Kovscek, A. R. [2001] Surfactant concentration and end effects on foam flow in porous media. Transport in Porous Media, 43, 511-536

Aronson, A.S., Bergeron, V., Fagan, M.E. and Radke, C.J. [1994] The influence of disjoining pressure on foam stability and flow in porous media. Colloids and Surfaces A: Physicochemical and Engineering Aspects, 83, 109-120

Boeije, C.S. and Rossen, W.R. [2013] Fitting foam simulation model parameters to data. Paper presented at the IOR 2013-17th European symposium on improved oil recovery, St. Petersburg

Ettinger, R. A., and Radke, C. J. [1992] Influence of texture on steady foam flow in Berea sandstone. SPE Reservoir Engineering, 7, 83-90

Falls, A.H., Musters, J.J. and Ratulowskl, J. [1989] The apparent viscosity of foams in homogeneous bead packs. SPE Reservoir Engineering, 4, 155-164

Farajzadeh, R, Andrianov, A., Bruining, J. and Zitha, P.L.J. [2009] Comparative study of $\mathrm{CO}_{2}$ and $\mathrm{N}_{2}$ foams in porous media at low and high pressure-temperatures. Industrial \& Engineering Chemistry Research, 48 (9). 4542-4552

Farajzadeh, R, Andrianov, A. and Zitha, P.L.J. [2010] Investigation of immiscible and miscible foam for enhancing oil recovery. Industrial \& Engineering Chemistry Research, 49 (4), 1910-1919

Farajzadeh, R., Andrianov A., Krastev R., Hirasaki, G. and Rossen, W.R. [2012] Foam-oil interaction in porous media: Implications for foam-assisted enhanced oil recovery. Advances in Colloid and Interface Science, 183-184, 1-13

Kapetas, L., Vincent-Bonnieu, S., Danelis, S., Rossen, W.R., Farajzadeh, R., Eftekhari1, A.A., Mohd Shafian, S. R. and Kamarul Bahrim, R. Z. [2014] Effect of temperature on foam flow in porous media. SPE 172820-MS (in preparation)

Khatib Z.I., Hirasaki G.J. and Falls A.H. [1988] Effects of capillary pressure on coalescence and phase mobilities in foams flowing through porous media. SPE Reservoir Engineering , 3, 919-926

Kovscek, A. R. and Bertin, H. J. [2003] Foam mobility in heterogeneous porous media. Transport in Porous Media, 52, 37-49

Kristiansen, T.S. and Holt, T. [1992] Properties of flowing foam in porous media containing oil. SPE/DOE 24182, 279-287

Lake, L.W. [1989] Enhanced Oil Recovery. Wiley, New York.

Ma, K., Lopez-Salinas, J. L., Puerto, M. C., Miller, C. A., Biswal, S. L. and Hirasaki, G. J. [2013] Estimation of parameters for the simulation of foam flow through porous media. Part 1 : The dry-out effect. Energy \& Fuels, 27, 2363-2375

Ma, K., Farajzadeh, R., Lopez-Salinas, J. L., Miller, C. A., Biswal, S. L. and Hirasaki, G. J. [2014] Non-uniqueness, numerical artifacts, and parameter sensitivity in simulating steady-state and transient foam flow through porous media. Transport in Porous Media, 102(3), 325-348

Mannhardt, K., Novosad, J.J. and Schramm, L.L. [2000] Comparative evaluation of foam stability to oil. SPE Reservoir Eval. \& Eng., 3 (1), 23-34 
Moradi-Araghi, A., Johnston, E.L., Zornes, D.R. and Harpole, K.J. [1997] Laboratory evaluation of surfactants for $\mathrm{CO}_{2}$-foam applications at the South Cowden Unit. SPE-37218-MS, 81-90

Nguyen, Q.P., Rossen, W.R., Zitha, P.L.J. and Currie, P.K. [2009] Determination of gas trapping with foam using X-ray computed tomography and effluent analysis. SPE Journal, 14, 222-236

Osterloh, W.T. and Jante, M.J. [1992] Effects of gas and liquid velocity on steady-state foam flow at high temperature. SPE/DOE 24179, 237-248

Persoff, P., Radke, C.J., Pruess, K., Benson, S.M. and Witherspoon, P.A. [1991] A laboratory investigation of foam flow in sandstone at elevated pressure. SPE Reservoir Engineering, 6, 365-372

Simjoo, M. and Zitha, P.L.J. [2013] Effects of oil on foam generation and propagation in porous media. SPE-165271-MS

Simjoo, M.; Rezaei, T., Andrianov, A. and Zitha, P.L.J. [2013] Foam stability in the presence of oil: Effect of surfactant concentration and oil type. Colloids and Surfaces A: Physicochemical and Engineering Aspects, 438, 148-158

van der Bent, V. [2014] Comparative study of foam stability in bulk and porous media. Master's thesis, TU Delft, Delft, The Netherlands

Vikingstad, A. K. and Aarra, M. G. [2009] Comparing the static and dynamic foam properties of a fluorinated and an alpha olefin sulfonate surfactant. Journal of Petroleum Science and Engineering, $\mathbf{6 5}, 105-111$

Zitha, P.L.J., Nguyen, Q.P., Currie, P.K and Buijse, M.A. [2006] Coupling of foam drainage and viscous fingering in porous media revealed by X-ray computed tomography. Transport in Porous Media, 64, 301-313 